\title{
The role of preparatory muscular tension in the size-weight illusion
}

\author{
CHRISTOPHER M. DAVIS and PAUL BRICKETT \\ Simon Fraser University, Burnaby, British Columbia, Canada V5A IS6
}

\begin{abstract}
Muscle action potentials were recorded from lifting muscles during the foreperiod before lifts of large and small objects when the size-weight illusion occurred. There were increases in tension throughout the foreperiod of both lifts, culminating in a large increase following the instruction to lift. The increases were greater before lifts of the large can, supporting the peripheral theory of comparative weight judgment. The "set to lift" effect was shown to exist in the action potentials before the foreperiod of the second lift when compared to those just prior to the lift of the first can.
\end{abstract}

Müller and Schumann (1889) proposed a motor theory of weight perception based on the relative ease with which objects are lifted. If the same effort were expended in the lifts of both objects of a pair, they concluded that the lighter object would be lifted more quickly and consequently feel lighter. Payne and R. C. Davis (1940) measured muscle action potentials before and during paired lifts and found that the preparatory tension before the first lift was, indeed, carried over to the foreperiod of the second and was reliably related to the relative judged heaviness of the second weight.

Furthermore, if ease of lifting determines perceived weight, then, when equally heavy objects are lifted with different forces, an illusory weight difference should result. C. M. Davis, Taylor, and Brickett (1977) manipulated lifting force by instruction and found that objects lifted "vigorously" usually felt lighter than identical objects lifted "gently." Altering the mechanical advantage of the hand-arm lever system caused the object lifted with relative mechanical advantage to feel lighter (C. M. Davis, 1973, 1974).

The size-weight illusion (SWI) may be another example of differing lifting forces producing perceived weight differences. Martin and Müller (1899) theorized that life's experience with large and small objects causes us to lift large objects with greater force, producing the illusory difference in weight. C. M. Davis and Roberts (1976) found that when the SWI occurred, the larger of two equally heavy cans was lifted with greater acceleration and peak velocity than the smaller.

According to the motor hypothesis of the SWI, muscular preparation for lifting should be a function of the size of the object to be lifted and should be reversed in the interlift period rather than "carried over" from the first lift as in the Payne and Davis study. Evidence

This research was supported by N.R.C. Grant A8611 to the first author. Requests for reprints should be sent to the Author, Department of Psychology, Simon Fraser University, Burnaby, B.C., Canada, V5A 1 S6. for the existence of preparatory muscle potentials, their time course, and relation to judgment category would provide a physical basis for "set to perceive" as well as suggest the sensory mechanisms through which muscular events are appreciated.

\section{METHOD}

\section{Subjects}

Twelve right-handed university students with normal vision and motor control were paid for serving.

\section{Apparatus}

The stimulus objects were 12 white paint cans, each weighing $500 \mathrm{~g}$, with rigid wire handles of equal width and height. Six were $1 / 2 \mathrm{pt}\left(236 \mathrm{~cm}^{3}\right)$ and six were $1 \mathrm{qt}\left(946 \mathrm{~cm}^{3}\right)$. Located under the table top from which the cans were lifted was a movement detector consisting of a weak permanent magnet surrounding a wire coil in which monetary currents were induced by can movements. Instructions to prepare to lift, and to lift, were signaled by light-emitting diodes (LEDs) on a display in front of the lifting platform in the subject's line of vision. Beckman silver-silver chloride electrodes were affixed over the right forearm flexors as described by J. F. Davis (Note 1).

\section{Recording Methods}

Action potentials were conducted to the adjoining room where they were amplified by a Grass Model 7P5 preamplifier and $7 \mathrm{D}$ ac driver amplifier. The driver output, amplified movement detector, and signal LED changes were digitized, temporarily stored in a Hewlett-Packard $2116 \mathrm{~b}$ computer in epochs of 1024 points per channel, and displayed on a laboratory oscilloscope before artifact-free data (artifacts were usually caused by premature lifts) were written on magnetic tape for off-line treatment." The 1-sec samples began $1 / 4$ sec before the $1 / 2-\mathrm{sec}$ "prepare to lift" signal and terminated with the $1 / 4-\mathrm{sec}$ "lift" signal.

\section{Procedure}

The subject's right wrist was taped palm-up to a padded horizontal board, which was the modified arm of the subject's chair. Fifteen by $15 \mathrm{~mm}$ blocks of polystyrene, grooved to fit the can handle on one side and shaped to the curvature of the finger on the other, were taped to the first and third fingers of the lifting hand over the middle phalanges. These guides ensured equal levers for all lifts and reduced the role of skin sensors. The cans were placed singly by the experimenter on the lifting platform so the subject could position the guides under the 
horizontal handle of the can to be lifted. The cans were arranged on a table near the lifting platform, and were selected and replaced by the experimenter in a pseudo-organized pattern of pairs, a large and small can to each pair.

Subjects were instructed that they would be lifting pairs of cans and judging whether the second can felt heavier, lighter, or equal to the first. After the subject made a number of practice lifts and the experimenter was satisfied that the lifts were consistent, paired comparison trials were begun. The interlift interval was 8 to $12 \mathrm{sec}$; the intertrial interval was approximately $30 \mathrm{sec}$. Data collected for each trial consisted of two 1-sec samples, one for each lift. The order of large and small cans was randomly varied. Trials were continued until the 20th occurrence of the SWI.

\section{Data Treatment}

MAP, movement, and signal data for SWI trials were averaged by can size and order for each subject. MAP data were rectified prior to averaging. The signal averages merely ensured that the recording system was operating correctly and were used to locate the point in MAP averages where signals occurred. The averaged movement data showed that no appreciable movement was recorded during the data sampling period (the $1 / 4 \mathrm{sec}$ following the instruction to lift was, after all, about one reaction time, so not much movement could have occurred). The smoothed MAP averages were plotted and the plots divided into quarters, the first quarter being the preinstruction period, the second and third the prepare to lift period, and the fourth the beginning of the lift period. The area of each quarter was measured using a compensating polar planimeter (Keuffel \& Esser Co., Model 620005 ). The resulting areas (in $\mathrm{cm}^{2}$ ) were apparently asymmetrically distributed and so were subjected to log transformation before analysis. Amplitude equivalence between subjects was ensured by comparing averaged calibration signals.

\section{RESULTS}

Figure 1 displays the averaged prelift muscular tension as a function of time and order for the two lifts of a pair. An analysis of variance confirmed that there were significant increases in tension in preparation for lifting, $F(3,33)=37.61, p<.01$. Indeed, the figure reveals that there was increasing mean tension before lifts of both cans from the earliest measurement, with the singular exception of the first $1 / 4 \mathrm{sec}$ (before the prepare-

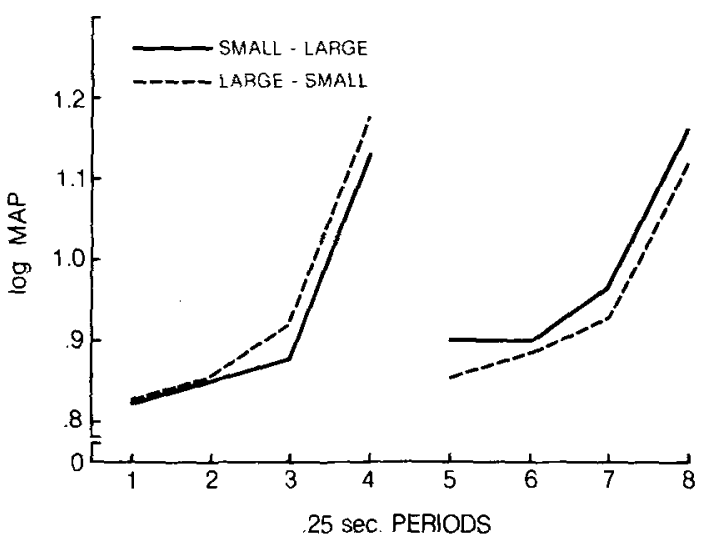

Figure 1. Log mean muscle action potential for $1 / 4-\mathrm{sec}$ intervals before lifts in paired-comparison trials. Periods 1 and 5 , before prepare-to-lift signal; Periods 2 and 3 and 6 and 7 , during prepare signal; and Periods 4 and 8 , following the lift signal. to-lift signal) of the large can lift following a small can lift. Subjects were, then, preparing to lift the cans well before they were instructed to do so.

Now these tensions, along with unrecorded synergistic and supporting tensions, must of necessity increase until they are sufficient to overcome the $500 \mathrm{~g}$ weight and any opposing tensions. Our interest was whether or not the recorded increases were related to subsequent heaviness judgments and, if so, how early in the preparation. Although, as Figure 1 shows, the large can was supported with greater mean tension than the small can at each respective $1 / 4-\mathrm{sec}$ period, the differences were not great enough to produce a reliable overall effect. However, the Can Size by Quartèr interaction was reliable, $F(3,33)=2.93, p<.05$, indicating that the development of muscular tension was affected by the size of the can about to be lifted. The other main effect in the analysis was the order of the lift, that is, whether it was first or second within each trial. Although the overall effect of order was not significant, $F(1,11)=2.80$, there was a significant Order by Quarter interaction, $F(3,33)=4.42, \mathrm{P}<.05$, which shows the developing tension to depend partly on the order of lifting.

The overall analysis reported above cannot well explore the occurrence of muscular set as it was originally conceived, namely as an interlift muscular adjustment based on the first lift, and the preparation for the second. If it is an interlift adjustment, then it would be most evident in our data in the last prelifting potentials from the first lift of the pair (the $1 / 4 \mathrm{sec}$ after the lift signal) and the earliest recorded potentials preceding the second lift of the pair (the $1 / 4 \mathrm{sec}$ before the ready signal). Accordingly, a separate 2 by 2 analysis of variance for Periods 4 and 5 for large and small cans found a significant main effect for size, $F(1,11)=7.74$, $p<$ .05 . As Figure 1 shows, greater MAP prior to lifts of the large cans in Period 4 is followed by reduced tension in the preparation to lift small cans in Period 5. This means that there is a relatively greater decrease in tension when the shift is from a large can to a small can.

Finally, in the experiment there were only three cases of "reversed SW," where the large can felt heavier than the small one. On all three trials, the preparatory MAP was greater for the small can throughout the measured foreperiod.

\section{DISCUSSION}

The increases in preparatory tension found in this study can be taken as support for a peripheral theory of comparative weight judgment. These results extend the Payne and R. C. Davis (1940) explanation by showing that the preparatory potentials are set for the first lift by the size of the object, and that rather than being "carried over" to the second lift, they are readjusted to correspond to the size of the second object to be lifted.

The genesis of the SWI clearly lies in muscular events 
beginning at least $1 / 2 \mathrm{sec}$ before the lift of the first can. The difference in the development of prelifting tension is almost entirely due to the greater increase in tension before large-can lifts during the last half of the ready signal. There was a steady, almost linear, increase in tension before lifts of the small can in both orders before the rapid increase following the instruction to lift. The large preparatory increases in tension after the lift signal are essentially parallel for large and small cans during Periods 4 and 8 , suggesting that the differential preparatory set is established early and then followed by a lifting command that is nearly the same for both cans. The neural basis may involve the preparation of the muscle for action via the muscle spindles proposed by Granit (1972), "The stronger command would have caused greater spindle discharge acting to facilitate the motoneurones" (p. 654). The ramifications of that adjustment for the MAP would be just those seen in our data in the increment between Periods 2 and 3 and 6 and 7 . This course of events is in accordance with Granit's recent (1975) description of two methods for muscular action: a preparedness device, where extrafusal tension is controlled by the gamma efferent loop, and the other, a coactivation of extra- and intrafusal muscle fibers related to the time course of movements.

Added to these developing differences was the significant interlift adjustment, the change from Period 4 to Period 5. There is no such initial adjustment before the first lift, where cans were approached with almost equal initial tension (Periods 1 and 2), but second lifts are prepared for in terms of the tension exerted in the first lift. Martin and Müller (1899) had long ago hypothesized this adjustment. The general theory of Müller and Schumann (1889), which stated that interlift adjustments based on the first lift of a pair were responsible for relative heaviness judgments, was extended by proposing that interlift adjustment in the SWI would also be influenced by experience with large and small objects. The interlift adjustment would be the reverse of the force applied in the first lift, large adjustments following small lifts and small adjustments following large lifts.

The lifting movements consequent to the muscular set would necessarily differ, at least in the early stages. And they do. C. M. Davis and Roberts (1976) found that a 1-qt $\left(946 \mathrm{~cm}^{3}\right)$ can was raised with greater peak acceleration and peak velocity than a $1 / 2$-pt $\left(236 \mathrm{~cm}^{3}\right)$ one when the SWI occurred but not when the illusion failed.

In view of these results, it might be suggested that the size of objects affects weight perception by the activation of preparatory muscular set which influences proprioception, rather than by the integration of size and weight information at some later stage of processing, as suggested by some theorists (Sjöberg, 1969). Experience adds to, or subtracts from, the muscular preparation for lifting so that the SWI may be less an illusion than a misapplication of lifting force. It is likely that the proprioceptive response to these force differences is similar to that which would result from lifting different masses with similar force.

However, the possibility remains that the effect of muscular set is either not responsible for the SWI, or, more likely, that it is no more than a contributing factor, as Cross and Rotkin (1975) suggest. The issue cannot be resolved from the data presented here, though the MAPs when the SWI was reversed are suggestive, but other misapplications have been shown to control weight perception. C. M. Davis $(1973,1974)$ found that altering the mechanical advantage of the hand-arm lever system through which hand-held objects were hoisted significantly affected judgment in the predicted direction. Objects requiring less force to lift were generally judged lighter. Indeed, the SWI was often reversed when the larger of an equal-weight pair was lifted from the fingertips and the smaller from the base of the fingers (C.M. Davis, 1973). Also, identical cans were made to feel differentially heavy when one was lifted vigorously and the other gently (C. M. Davis et al., 1977).

More generally, these results confirm that covert muscular events anticipate overt ones, and, in this case, with ramifications for perception.

\section{REFERENCE NOTE}

1. Davis, J. F. Manual of surface electromyography. WADC Technical Report 59-184, December 1959.

\section{REFERENCES}

Cross, D. V., \& Rotkin, L. The relation between size and apparent heaviness. Perception \& Psychophysics, 1975, 18, 79-87.

DAvis, C. M. Mechanical advantage in the size-weight illusion. Perception \& Psychophysics, 1973, 13, 238-240.

Davis, C. M. The role of effective lever length in the perception of lifted weights. Perception \& Psychophysics, 1974, 16, 67-69.

Davis, C. M., \& RoBerts, W. Lifting movements in the sizeweight illusion. Perception \& Psychophysics, 1976, 20, 33-36.

Davis, C. M., TaYlor, M., \& BricketT, P. A weight illusion produced by lifting movements. Perceptual and Motor Skills, 1977, 44, 299-305.

Granit, R. Constant errors in the execution and appreciation of movement. Brain, 1972, 95, 649-660.

Granit, R. The functional role of the muscle spindles-facts and hypotheses. Brain, 1975, 98, 531-556.

Martin, L., \& Müller, G. E. Zur Analyze der Untershiedsempfindlichkeit. Leipzig: Barth, 1899.

Müller, G. E., \& Schumann, F. Ueber die psychologischen Grundlagen der Vergleichung gehobener Gewichte. Archives für die Gesamte Physiologie, 1889, 45, 37-112.

Payne, B., \& Davis, R. C. The role of muscular tension in the comparison of lifted weights. Joumal of Experimental Psychology, 1940, 27, 227-242.

SJöBERG, L. Sensation scales in the size-weight illusion. Scandinavian Journal of Psychology, 1969, 10, 109-112.

\section{NOTE}

1. Both the software and hardware for computer data collection and experimental control were designed and implemented by Mr. Howard Gabert, Professional Engineer.

(Received for publication October 4, 1976; revision received May $9,1977$. 